\title{
NUMERICAL SIMULATION OF THE BLAST-RESISTANT RESPONSE OF ULTRAHIGH-PERFORMANCE CONCRETE STRUCTURAL MEMBERS
}

\author{
Hor YIN®1, Kazutaka SHIRAI(12 ${ }^{*}$, Wee TEO ${ }^{3}$ \\ ${ }^{1}$ Graduate School of Engineering, Hokkaido University, Sapporo, Japan \\ ${ }^{2}$ Faculty of Engineering, Hokkaido University, Sapporo, Japan \\ ${ }^{3}$ School of Energy, Geoscience, Infrastructure and Society, Heriot Watt University Malaysia, Putrajaya, Malaysia
}

Received 18 December 2018; accepted 22 March 2019

\begin{abstract}
This paper presents the blast responses of ultrahigh-performance concrete (UHPC) structural members obtained using finite element (FE) modelling. The FE model was developed using LS-DYNA with an explicit solver. In the FE simulation, the concrete damage model, which is a plasticity-based constitutive material model, was employed for the concrete material. The simulation results were verified against previous experimental results available in the literature and were shown to be in good agreement with the experimental results. In addition, the developed FE model was implemented in a parametric study by varying the blast weight charges. The numerical results for UHPC members were compared with those for conventional reinforced concrete (RC) members. The numerical responses, such as the maximum deflections, deflected shapes, and damage patterns, of the UHPC members subjected to blast loading were significantly better performance than those of the RC members as a result of the high strength and ductile capacity of UHPC.
\end{abstract}

Keywords: finite element modelling, blast simulation, UHPC member, structural behaviour, concrete structure, static and blast loading.

\section{Introduction}

The behaviour of nonlinear structural members, such as reinforced concrete (RC) members, during explosions is a complex issue because of the short duration and high amplitude of such blasts (CEB-FIP Model Code, 1990; Ngo, Mendis, \& Krauthammer, 2007). In addition, although accidental or intentional explosions rarely occur, blast damage to RC structures can produce disastrous consequences. Short-duration blast loads impart an extremely large amount of energy to the structures and can excite global or local responses. The excitement of the blast effect may cause the immediate failure of structural members or heighten the risk of the progressive collapse of whole structures. It is thus necessary to explore the use of new and innovative materials that can improve structural performance under blast loading.

With the advancement of concrete technology, ultrahigh-performance concrete (UHPC) has been developed with exceptional properties, such as high compressive strengths exceeding $150 \mathrm{MPa}$, strain hardening, ductility, and superior damage tolerance (Richard \& Cheyrezy, 1995; Wille, Naaman, \& Parra-Montesinos, 2011; Wu, Oe-

hlers, Rebentrost, Leach, \& Whittaker, 2009). The integration of UHPC into structural members is effective against blast loading because the high strength and ductility of UHPC can help mitigate deflection and damage. According to previous experimental studies (Yi, Kim, Han, Cho, \& Lee, 2012; Li, Wu, Hao, Wang, \& Su, 2016; Li, Wu, Hao, \& Su, 2017; Mao, Barnett, Begg, Schleyer, \& Wight, 2014; Mao et al., 2015), the inclusion of UHPC structural members under blast loading significantly enhances the blast resistance capacity in comparison with that of conventional RC members made of normal-strength concrete (NSC).

However, studies on the blast response of UHPC members using the finite element (FE) method, which is one of the most effective tools for structural performance analysis, have been very limited (Mao et al., 2014; Li, Wu, Hao, \& Su, 2015). The FE models developed by Mao et al. (2014) and Li et al. (2015) could reasonably predict the maximum deflection and damage pattern of UHPC panels under blast loading, but the evolution of the deflected shapes of the members was not reported. In addition, investigation on the effectiveness of UHPC members in comparison

^Corresponding author. E-mail: shirai.kazutaka@eng.hokudai.ac.jp 
with that of conventional RC members using FE modelling has not yet been clearly reported. This means much work on relevant FE methods remains to be carried out to address the issue of blast loading.

The main objective of the present study was to investigate the blast-resistant response of UHPC members using FE modelling. Blast simulations were conducted for both UHPC and RC members. The simulation results were verified against previous experimental results available in the literature. In addition, a numerical assessment with various blast weights was carried out to evaluate the effectiveness of UHPC members in comparison with that of conventional RC members. Comparisons of simulation results included the maximum deflections, deflected shapes, and damage patterns of the two types of members.

\section{Finite element modelling}

\subsection{Modelling and conditions}

In this study, the behaviour of UHPC members was numerically investigated. The general-purpose FE software package LS-DYNA (Hallquist, 2016) was used for the numerical simulation. Both NSC and UHPC were modelled using eight-node constant-stress solid elements. For longitudinal rebar, a two-node beam element was used. The adopted mesh sizes of the FE model were based on a convergence investigation. A perfect bond between longitudinal rebar and concrete was assumed; to this end, the longitudinal rebar was embedded in the concrete (NSC and UHPC).

Yin, Shirai, and Teo (2019a) have analytically investigated on the effect of mesh size by varying sizes of an eight-node cubic element model. In the present study, a preliminary analysis on mesh convergence was carried out using the same method as conducted by Yin et al. (2019a). Although details of the analysis were omitted here, similar to findings by Yin et al. (2019a), the mesh sizes of 5 through $20 \mathrm{~mm}$ could be used in the present paper.

The loading and support boundaries were modelled to represent the actual conditions of specimens used for verification (Section 3.1). Two loading types, static and blast loads were considered in this study. For the static simulations, both implicit and explicit analyses in LS-DYNA were adopted, and displacement-controlled loading was used.

For the blast response simulations, only the explicit method was used. The details of the loading conditions are given in Section 2. According to the results of the blast experiments reported by Yi et al. (2012), both displacement and acceleration response of time history waveforms gradually decreased as time proceeded. To consider such behaviour in the blast simulation, a global damping system in LS-DYNA was adopted in the present study. Through several trials, it was found that the most appropriate damping ratio was 5\%, and this ratio was applied to all blast simulations in this study.

\subsection{Material model for concrete}

Several material models in LS-DYNA, such as Mat Johnson Holmquist Concrete (Mat-111), Mat Pseudo Tensor (Mat-16), Mat CSCM Concrete (Mat-159), and Mat Concrete Damage (Mat-72r3), can be used to configure the behaviour of concrete. In the present study, the concrete damage model (Mat-72r3), a plasticity-based constitutive model (Malvar, Crawford, Wesevich, \& Simons, 1997), was employed for both the NSC and UHPC because it has been demonstrated to show high reliability (Li \& Zhang, 2011; Li \& Hao, 2014).

The major advantage of the concrete damage model Mat-72r3 is that only a single parameter, the unconfined compressive concrete strength $f_{c}^{\prime}$, is required as an input. The remaining parameters are automatically generated using a built-in algorithm and can also be modified by the user.

The concrete damage model is defined by three independent strength surfaces: an initial yield surface, a maximum failure surface, and a residual surface. The function of each of these strength surfaces can be expressed as (Magallanes, Wu, Malvar, \& Crawford, 2010):

$$
F_{i}(p)=a_{0 i}+\frac{p}{a_{1 i}+a_{2 i} p},
$$

where $p$ is the pressure; $F_{i}$ is the $i$ th failure surface; and $a_{0 i}$, $a_{1 i}$, and $a_{2 i}$ are parameters defining the three-parameter failure surfaces.

The surface interpolation is accomplished by internally scaling the softening and hardening of the variable $\eta$, which is determined from the damage function $\lambda$ as:

$$
\lambda= \begin{cases}\int_{0}^{\overline{\varepsilon_{p}}} \frac{d \overline{\varepsilon_{p}}}{\left(1+p / f_{t}\right)^{b_{1}}} & p \geq 0 \\ \overline{\varepsilon_{p}} \frac{\overline{d \varepsilon_{p}}}{\left(1+p / f_{t}\right)^{b_{2}}} & p<0\end{cases}
$$

where $\overline{\varepsilon_{p}}$ is the effective plastic strain; $b_{1}$ and $b_{2}$ are the damage parameters for configuring the concrete hardening and softening behaviour, respectively; and $f_{t}$ is the quasi-static concrete tensile strength.

The value of $\eta$ varies from 0 to 1 depending on the accumulated effective plastic strain parameter $\lambda$. The full details of the parameters can be found in the original study (Malvar et al., 1997).

\section{Equation of state}

An equation of state (EOS) with tabulated compaction was employed in the concrete damage model Mat-72r3. The tabulated compaction model is multi-linear in internal energy. The pressure $p$ in the loading phase is given as a function of volumetric strain $\varepsilon_{v}$, as (Hallquist, 2016):

$$
p=C\left(\varepsilon_{v}\right)+\gamma T\left(\varepsilon_{v}\right) E,
$$

where $\varepsilon_{v}$ is the logarithmic volumetric strain, $C$ and $T$ are coefficients that are functions of $\varepsilon_{v}, \gamma$ is the specific heat ratio, and $E$ is the internal energy. 
When it is necessary, modification of this EOS in the simulation was adopted for the stiffness correction of UHPC members (Yin et al., 2019a). The parameters $b_{1}$ and $b_{2}$ in Eqn (2) are used in the concrete damage model to configure the concrete hardening and softening behaviour. The values of $b_{1}$ and $b_{2}$ might be modified to reflect the actual behaviour of UHPC after the modification of EOS. According to Yin et al. (2019a, 2019b), changes in the compressive parameter $b_{1}$ did not significantly affect the behaviour of UHPC, whereas changes in the tensile softening parameter $b_{2}$ demonstrated a clear effect. In the present study, the material model for UHPC was calibrated by changing the parameter $b_{2}$ based on the same approach as performed by Yin et al. (2019a).

\section{Strain rate effect}

As is commonly known, concrete is a strain-rate-dependent material. The strength characteristic of concrete under blast loading (strain rate of $10^{-1}$ to $10^{3} \mathrm{~s}^{-1}$ ) is significantly higher than that under a quasi-static event (strain rate of $10^{-6}$ to $10^{-4} \mathrm{~s}^{-1}$ ). The dynamic increase factor (DIF), which is defined as the ratio of the dynamic strength to the static strength, has been used to consider the effect of strain rate in the material.

For NSC, the DIFs under compression and tension can be obtained using existing empirical models (CEB-FIP Model Code, 1990). For UHPC, investigation on the strain rate effect has been very limited. Ngo et al. (2007) proposed a method of determining the DIF for UHPC based on a compressive strength of $160 \mathrm{MPa}$; at given strain rate of $300 \mathrm{~s}^{-1}$, they obtained a DIF of 1.5. Teng, Chu, Chang, Shen, and Cheng (2008) used a constant DIF of 1.5 in their numerical simulation on the impact response of fibre-reinforced concrete members; however, a constant DIF may lead to high overestimates of the response. In addition, the DIF was not considered in the numerical models of Z. Wang, Wu, and J. Wang (2010) in their simulation of the penetration of fibre-reinforced concrete members or those of Li et al. (2015) in their blast response analysis of UHPC members; however, their numerical results showed good performance.

Recently, some studies on DIFs for the UHPC material have been conducted (Thomas \& Sorensen, 2017). Millard, Molyneaux, Barnett, and Gao (2010) used drop-hammer techniques to investigate the DIF under both flexural and shear high-speed loading of blast-resistant UHPC. It was found that the strain rate enhancement of flexural strength for UHPC is reduced as the fibre percentage increases from $0 \%$ to $6 \%$, and in the case of shear loading, there is no significant DIF observed. Pyo, El-Tawil, and Naaman (2016) conducted tests for direct tensile behaviour of UHPC at strain rates from 90 to $146 \mathrm{~s}^{-1}$. They evaluated the DIF in terms of first cracking strength, post-cracking strength, energy absorption capacity, and strain capacity. Under increasing strain rates, UHPC showed exceptional rate sensitivities in energy absorption capacity. However, full details of DIFs that can be used for FE modelling on the dynamic behaviour of UHPC have not been yet confirmed (Oth- man, Marzouk, \& Sherif, 2019). In the present study, as in the work done by Wang et al. (2010) and Li et al. (2015), the strain rate effect was not considered for the FE simulation of the concrete materials (NSC and UHPC).

\subsection{Material model for longitudinal rebar}

For the longitudinal reinforcement, the LS-DYNA material model Mat-03, which is an elastic-plastic model with kinematic and isotropic hardening, was used in the present study. The reliability of this model has been demonstrated in previous works (Lin, Zhang, \& Hazell, 2014; W. Chen, Hao, \& S. Chen, 2015).

As with the concrete material, the strain rate effect was not considered in the simulation of the longitudinal rebar.

\section{Loading conditions}

\subsection{Static loading}

In the static simulation with the implicit solver, a static loading rate of $2 \times 10^{-5} \mathrm{~m} / \mathrm{s}$ was used. The implicit method is commonly used to solve iterative equations and can be effectively applied to static problems because it is unconditionally stable for large time increments. However, the numerical solution of this method is often inaccurate when the convergence of the equilibrium iterations is difficult to achieve.

In addition, the explicit method, which directly solves the problem without iterations, was also adopted to assess the static behaviour. However, the explicit method is conditionally stable and requires very small time increments to guarantee accuracy. The explicit solution for the static problems thus inevitably leads to a large number of time steps. The simulation time can be reduced by either reducing the total number of time steps or increasing the time increment, and the results can be considered acceptable when the kinetic energy is negligible in comparison with the internal energy of the model. In the present investigation with the explicit solver, an increased loading rate of $2 \times 10^{-3} \mathrm{~m} / \mathrm{s}$ was adopted to reduce the total number of time steps.

Static loading was applied directly to the node sets of the FE model of the specimens. Displacement-controlled loading was used for both the implicit and explicit methods.

\subsection{Blast loading}

\subsubsection{Overview}

High explosives create shock waves and can burst, shatter, penetrate, lift or heave materials. When a high explosive detonates in air, it produces an air blast (Mays \& Smith, 1995). The high pressure causes a violent expansion of the gaseous products of the explosive reaction, and the surrounding air is forced out of the volume it occupies. This layer of air contains most of the explosive energy and is known as the blast wave. Because a disequilibrium is set up between the highly compressed air in the blast wave 


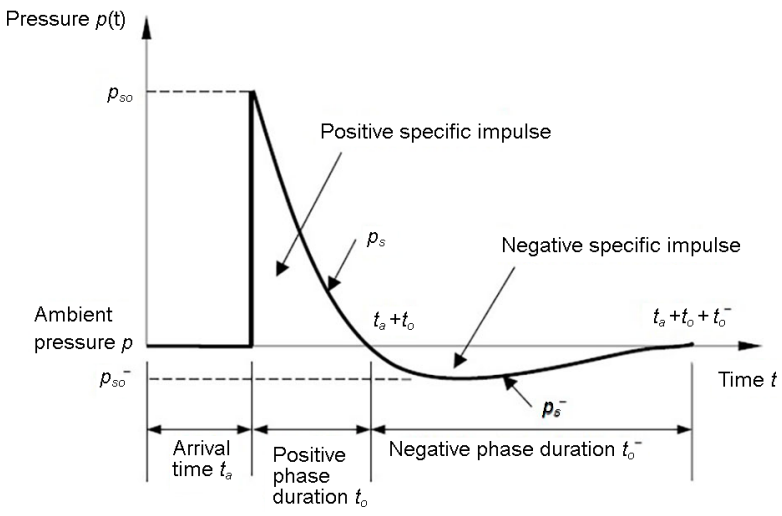

Figure 1 . Time history of the blast pressure during an explosion (US Department of the Army, 1990)

and the undisturbed air in front of it, the blast wave travels outwards from the centre of the explosion. At this point, the total energy in the system is constant because the explosive has now fully detonated. The pressure at the blast wave front decreases as the wave front travels further from the explosion. The momentum of the gas causes it to overexpand and results in the pressure at the tail of the blast wave falling below the air pressure of the atmosphere. The resulting removal of the air from the atmosphere creates a negative pressure phase, causing the flow to reverse back towards the explosion centre. Eventually equilibrium is restored to the ambient air.

Figure 1 shows a typical pressure profile of a blast wave over time for an explosion occurring in free air. The peak pressure of the negative phase is typically small in comparison with that of the positive phase.

The pressure time history of a blast wave can be described as an exponential function, i.e. the Friedlander equation, which is given as

$$
p(t)=p_{s o}\left(1-\frac{t}{t_{a}}\right) \exp \left\{-\frac{\alpha t}{t_{o}}\right\},
$$

where $t$ is the wave duration, $t_{a}$ is the arrival time, $t_{o}$ is the duration of the positive phase, $p_{s o}$ is the peak overpressure, and $\alpha$ is a waveform parameter. The peak overpressure produced by the spherical blast wave is given as a function of the scaled distance $Z=R / W^{1 / 3}$, where $R$ [m] is the actual effective distance from explosion in and $W$ $[\mathrm{kg}]$ is the blast charge weight of trinitrotoluene (TNT).

The empirical equations for the peak overpressure $p_{s o}$ [bar] under a spherical air burst are as follows (Brode, 1955):

$$
\begin{aligned}
& p_{s o}=\frac{6.7}{Z^{3}}+1 \quad\left(p_{s o} \geq 10 \text { bar }\right) \\
& p_{s o}=\frac{0.975}{Z}+\frac{1.455}{Z^{2}}+\frac{5.85}{Z^{3}}-0.019 \\
& \left(0.1 \text { bar } \leq p_{s o}<10 \text { bar }\right) .
\end{aligned}
$$

Mills (1987) provided the following expression for the peak overpressure $p_{\text {so }}[\mathrm{kPa}]$ :

$$
p_{s o}=\frac{1772}{Z^{3}}-\frac{114}{Z^{2}}+\frac{108}{Z}
$$

where $W[\mathrm{~kg}]$ is the charge weight of TNT and $Z$ is the scaled distance.

\subsubsection{Blast load modelling}

In the present study, the blast loading was modelled using a load-blast-enhanced function. In LS-DYNA, this function is based on the empirical model described in the TM5-855 US army handbook (CONWEP) (US Department of the Army, 1990). The load-blast-enhanced function is commonly used by many researchers and has been shown to yield high reliability (Mao et al., 2014; Li \& Hao, 2014; Lin et al., 2014; Chen et al., 2015).

The major advantage of the blast-enhanced function is that it can avoid the detailed modelling of the explosive charge and shock wave in air. The function requires only the equivalent mass of TNT, the location of the detonation charge, and the type of blast. The blast type used in the present simulation was the spherical free-air burst.

\subsubsection{Blast pressure response}

The incident pressures obtained using blast load modelling as described above were compared with those measured at a distance of $5 \mathrm{~m}$ in the experiment performed by Yi et al. (2012). As shown in Figure 2, as with the numerical results conducted by Yi et al. (2012), the present numerically obtained pressure agreed well with the first peak pressure of the experimental results. In addition, the reflected pressures, which are similar to the incident pressures, were computed using the Unified Facilities Criteria (UFC 3-340-02, 2008) and are depicted in Figure 2 for comparison.

\section{Numerical simulations}

\subsection{Database description}

In the present study, eight specimens were chosen from open documents (Li et al., 2015; Yi et al., 2012; Yin, Teo, \& Shirai, 2017). The geometries and material properties adopted in the simulations of the specimens are listed in Table 1.

Two UHPC specimens were tested by Li et al. (2015). One was tested under static loading, and the other was tested under blast loading. A four-point bending system was used for the static testing of the $100 \times 100 \times 400 \mathrm{~mm}$ UHPC specimen, named MF15, with no reinforcement rebar. A blast test was conducted on the $200 \times 200 \times 2500 \mathrm{~mm}$ UHPC specimen, named U1B1. Specimen U1B1 was reinforced with six longitudinal rebar of $16 \mathrm{~mm}$ in diameter (6Ø16). A blast charge of $1 \mathrm{~kg}$ TNT was hung over the centre of the specimen at a height of $1500 \mathrm{~mm}$. The full details of the experiment can be found in Li et al. (2015).

Four specimens were reported by Yi et al. (2012). Two of the specimens, named NSC1 and NSC2, were made of 


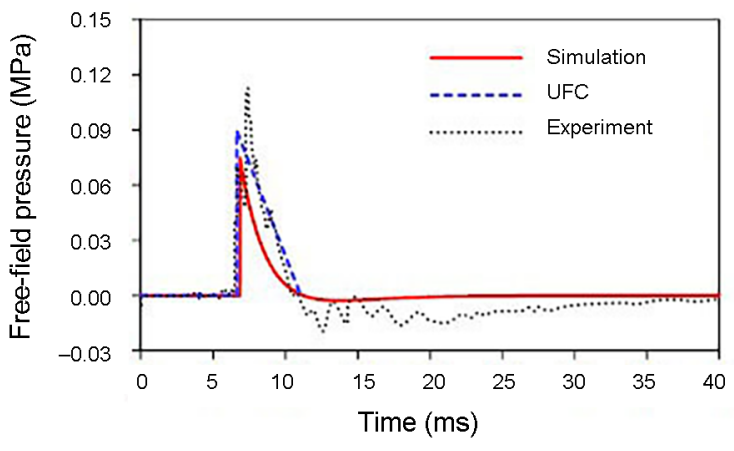

(a) $4.08 \mathrm{~kg}$ TNT

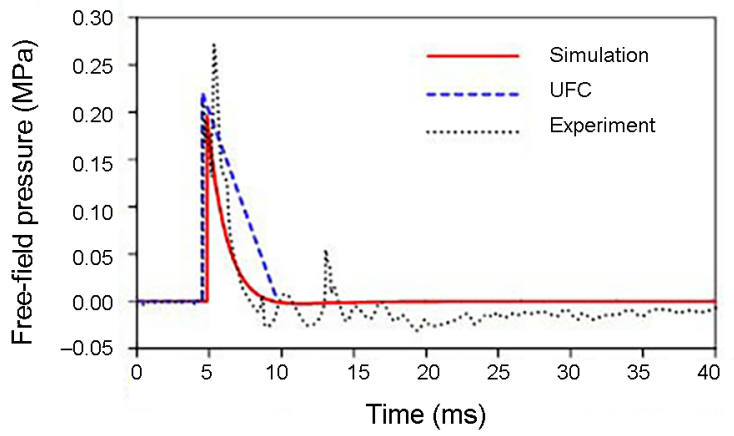

(b) $15.88 \mathrm{~kg}$ TNT

Figure 2. Free-field pressures obtained using the present FE model, UFC 3-340-02 (2008), and in the experiment performed by Yi et al. (2012)

NSC, and the other two, named RPC1 and RPC2, were made of UHPC. Each specimen was reinforced with two layers of mesh reinforcements of $10 \mathrm{~mm}$ in diameter in both directions. The blast charge was installed at a height of $1500 \mathrm{~mm}$ above the centre of the specimens. Specimens NSC1 and NSC2 were respectively tested under blast charges of $15.88 \mathrm{~kg}$ TNT and $15.88 \mathrm{~kg}$ ammonium nitrate/ fuel oil (ANFO), which has a TNT equivalence of 0.82 . For UHPC specimens, both RPC1 and RPC2 were tested under the same blast weight of $15.88 \mathrm{~kg}$ ANFO. The full details can be found in Yi et al. (2012).

The last two specimens were tested under static loading by Yin et al. (2017). One was made of NSC and the other was made of UHPC; these are named RE-0 and RE-100, respectively. The specimens had five high-tensile-strength steels of $12 \mathrm{~mm}$ in diameter (5DB12) installed along both the bottom and top as longitudinal reinforcement. Figure 3 shows the details of the cross sections of the specimens. Although these specimens were tested under static conditions in the experiments, they were numerically studied under blast loading. In the present paper, the static $\mathrm{FE}$ analysis was first validated against the experimental re-

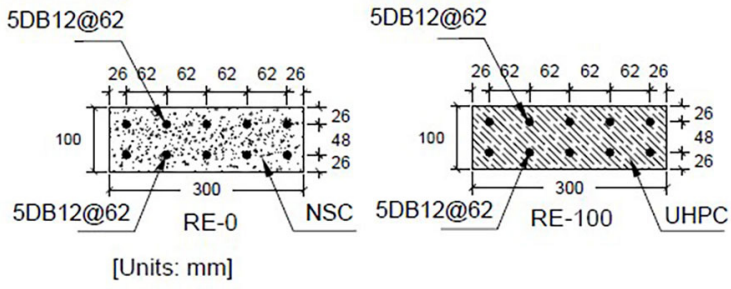

Figure 3. Details of the cross sections of specimens tested by Yin et al. (2017)

sults, and then blast simulations based on the FE model used in the static simulation were investigated under different blast charges.

\subsection{Simulation results}

\subsubsection{Specimens by Li et al. (2015)}

The static specimen MF15 tested by Li et al. (2015) was modelled using a 10-mm mesh. The FE model described in Section 1 was implemented. The FE model was individually calibrated for the implicit and explicit solvers to

Table 1. Geometries, loading conditions, and material properties adopted in simulations of specimens

\begin{tabular}{|c|c|c|c|c|c|c|c|c|c|c|}
\hline \multirow[b]{2}{*}{ Author } & \multirow[b]{2}{*}{ Specimen } & \multirow{2}{*}{$\begin{array}{l}\text { Loading } \\
\text { (blast charge) }\end{array}$} & \multicolumn{3}{|c|}{ Geometry } & \multirow{2}{*}{ 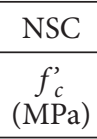 } & \multirow{2}{*}{$\begin{array}{c}\text { UHPC } \\
\begin{array}{c}f_{c}^{\prime} \\
(\mathrm{MPa})\end{array}\end{array}$} & \multicolumn{3}{|c|}{ Longitudinal steel } \\
\hline & & & $\begin{array}{c}W \\
(\mathrm{~mm})\end{array}$ & $\begin{array}{c}H \\
(\mathrm{~mm})\end{array}$ & $\begin{array}{c}L \\
(\mathrm{~mm})\end{array}$ & & & $\begin{array}{c}\phi \\
(\mathrm{mm})\end{array}$ & $\begin{array}{c}f_{y} \\
(\mathrm{MPa})\end{array}$ & $\begin{array}{l}f_{y, \max } \\
(\mathrm{MPa})\end{array}$ \\
\hline \multirow{2}{*}{$\begin{array}{l}\text { Li et al. } \\
\text { (2015) }\end{array}$} & MF15 & Static & 100 & 100 & 400 & - & 150 & - & - & - \\
\hline & U1B1 & Blast (1 kg TNT) & 200 & 200 & 2500 & - & 150 & 16 & 1350 & 1600 \\
\hline \multirow{4}{*}{$\begin{array}{l}\text { Yi et al. } \\
(2012)\end{array}$} & NSC1 & Blast (15.88 kg TNT) & 1000 & 150 & 1000 & 25.6 & - & 10 & 400 & 600 \\
\hline & NSC2 & Blast (15.88 kg ANFO) & 1000 & 150 & 1000 & 25.6 & - & 10 & 400 & 600 \\
\hline & RPC1 & Blast (15.88 kg ANFO) & 1000 & 150 & 1000 & - & 202.9 & 10 & 400 & 600 \\
\hline & RPC2 & Blast (15.88 kg ANFO) & 1000 & 150 & 1000 & - & 202.9 & 10 & 400 & 600 \\
\hline \multirow{2}{*}{$\begin{array}{l}\text { Yin et al. } \\
(2017)\end{array}$} & RE-0 & Static/blast (1-10 kg TNT) & 300 & 100 & 1600 & 23 & - & 12 & 502 & 565 \\
\hline & RE-100 & Static/blast (1-10 kg TNT) & 300 & 100 & 1600 & - & 153 & 12 & 502 & 565 \\
\hline
\end{tabular}

Notes: $W$ - width; $H$ - total height; $L$ - total longitudinal length; $f_{c}^{\prime}-$ compressive strength of NSC or UHPC; $\phi$ - diameter of reinforcement; $f_{y}$ - yield strength of reinforcement; $f_{y, \max }$ - ultimate strength of reinforcement; TNT - trinitrotoluene; ANFO ammonium nitrate/fuel oil. 
Table 2. Concrete model parameters employed in numerical simulation

\begin{tabular}{|c|c|c|c|c|c|c|c|c|c|}
\hline \multirow[b]{2}{*}{ Author } & \multirow[b]{2}{*}{ Specimen } & \multicolumn{4}{|c|}{ Implicit analysis } & \multicolumn{4}{|c|}{ Explicit analysis } \\
\hline & & $\begin{array}{c}f_{c}^{\prime} \\
(\mathrm{MPa})\end{array}$ & $\begin{array}{c}f_{t} \\
(\mathrm{MPa})\end{array}$ & $b_{2}$ & $\begin{array}{c}w_{c} \\
(\mathrm{~mm})\end{array}$ & $\begin{array}{c}f_{c}^{\prime} \\
(\mathrm{MPa})\end{array}$ & $\begin{array}{c}f_{t} \\
(\mathrm{MPa})\end{array}$ & $b_{2}$ & $\begin{array}{c}w_{c} \\
(\mathrm{~mm})\end{array}$ \\
\hline \multirow{2}{*}{ Li et al. (2015) } & MF15 & 150 & 17 & -12 & 35 & 150 & 23 & -38 & 15 \\
\hline & $\mathrm{U} 1 \mathrm{~B} 1$ & - & - & - & - & 150 & 23 & -38 & 15 \\
\hline \multirow{2}{*}{ Yi et al. (2012) } & NSC1, NSC2 & - & - & - & - & 25.6 & 3 & -1 & 15 \\
\hline & RPC1, RPC2 & - & - & - & - & 202.9 & 12 & 1.35 & 15 \\
\hline \multirow{2}{*}{ Yin et al. (2017) } & RE- 0 & 23 & 3 & -10 & 25.18 & 23 & 3 & -10 & 25.18 \\
\hline & RE-100 & 153 & 10.5 & -25 & 13 & 153 & 10.5 & -8 & 10 \\
\hline
\end{tabular}

Notes: $f_{c}^{\prime}$ - compressive strength of UHPC; $f_{t}$ - tensile strength of UHPC; $b_{2}$ - tension softening concrete parameter of concrete damage model; $w_{c}$ - localised crack width of concrete damage model.

yield good predictions. The concrete model parameters obtained from the calibration used in the FE model are listed in Table 2.

Figure 4 shows the static load-deflection curves obtained from the numerical simulation and the experiment. When equal parameters were used in the FE model for both the implicit and explicit methods, the numerical peak load from explicit method was significantly less than that from the implicit method, as shown in Figure 4(a). The FE model in the explicit method was then recalibrated with a new set of concrete model parameters. With these newly calibrated parameters (Table 2), the load-deflection curve obtained using the explicit method was in good agreement with the experimental curve, as shown in Figure 4(b). Thus, these parameters for the explicit method were used in the blast simulation.

The full-scale blast specimen U1B1 tested by Li et al. (2015) was modelled using a $20-\mathrm{mm}$ mesh. The material models described in Section 1 were implemented. The supports were modelled using solid rigid panels and constrained in all directions. The overall configuration of the model setup for the blast simulation of specimen U1B1 is shown in Figure 5. As mentioned previously, the global damping system was used. The damping constant of the global damping system in LS-DYNA was determined such that damping ratio was $5 \%$.

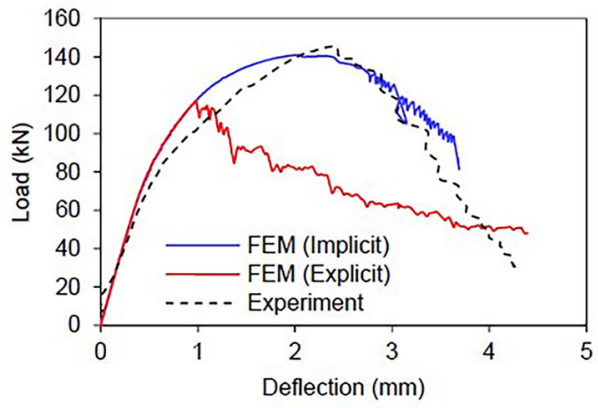

(a) Application of equal parameters to both implicit and explicit methods

Note:

${ }^{*}$ Newly calibrated parameters for explicit method

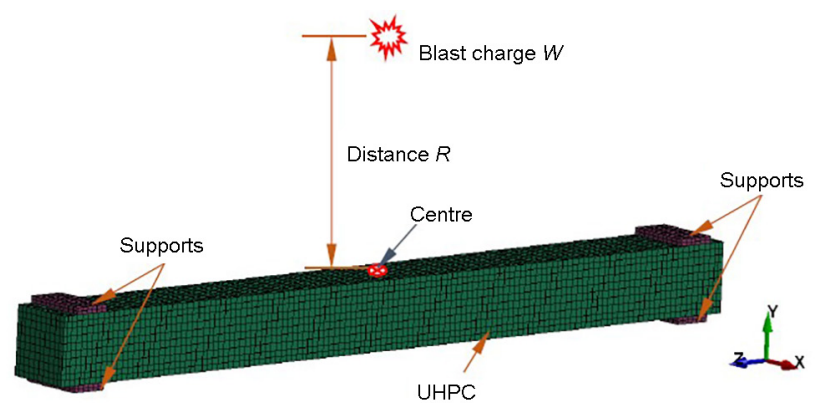

Figure 5. Overview of FE model for the blast simulation of the specimen tested by Li et al. (2015)

Figure 6(a) and (b) respectively shows the experimental results and numerical responses without the damping effect and with the damping ratio set to $5 \%$. As shown in Figure 6(a), the numerical simulation results were indicative of an undamped free vibration. When a damping ratio of $5 \%$ was applied in the FE model, the numerical response showed reasonable agreement with the experimental results, as shown in Figure 6(b). However, for the maximum response at the first cycle deflection, there was not much difference between the case with damping (Figure 6(b)) and without damping (Figure 6(a)).

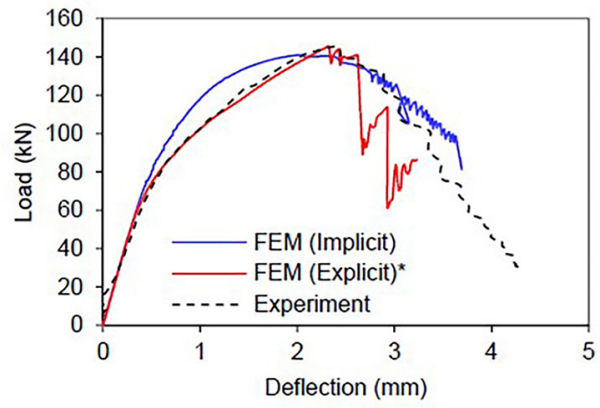

(b) Application of modified parameters to explicit method

Figure 4. Load-deflection curves for static specimen MF15 tested by Li et al. (2015) 


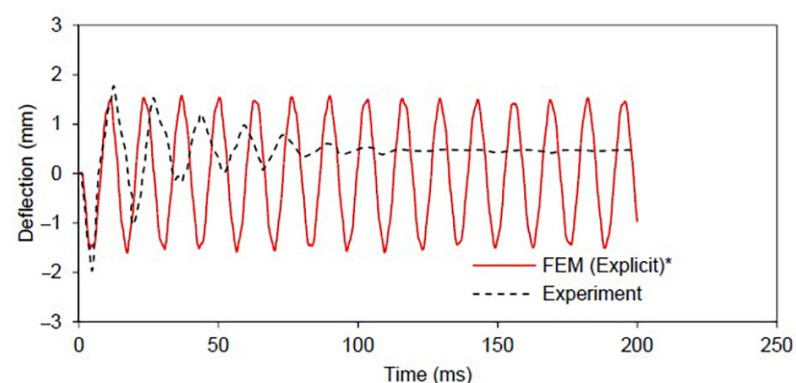

(a) No damping effect taken into account

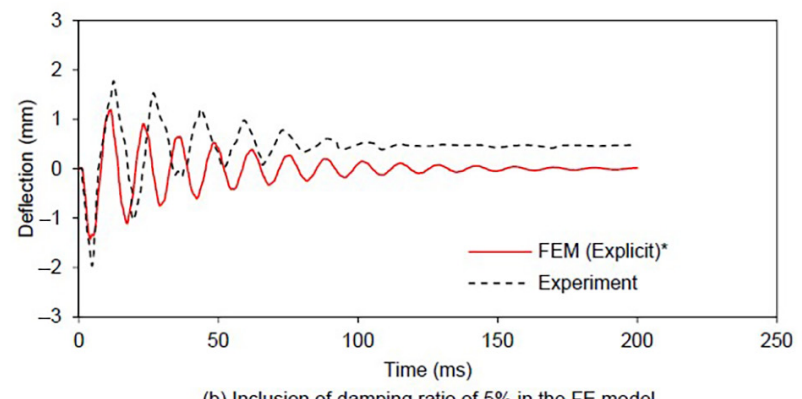

(b) Inclusion of damping ratio of $5 \%$ in the FE model

Note:

* Newly calibrated parameters for explicit method

Figure 6. Comparison of deflection time histories for specimen U1B1 tested by Li et al. (2015) under blast loading

\subsubsection{Specimens by Yi et al. (2012)}

The specimens tested by Yi et al. (2012) were modelled using a $20-\mathrm{mm}$ mesh. The supports were modelled using solid rigid panels and constrained in all directions. The overall configuration of the FE model is shown in Figure 7. The concrete damage model parameters used for the NSC and UHPC specimens are listed in Table 2.

Figure 8(a) and (b) respectively shows the experimental results and numerical responses without the damping effect and with a damping ratio of 5\% for specimen NSC1. As shown in Figure 8(a), the numerical simulation results showed damped free vibration after the first cycle of deflection time history as a result of the nonlinear hysteresis behaviour of the reinforced NSC member. When a damping ratio of 5\% was included in the FE model, the residual deflection obtained from the numerical simulation agreed well with the experimental results, as shown in Figure 8(b). The maximum deflection obtained in the numerical simu-

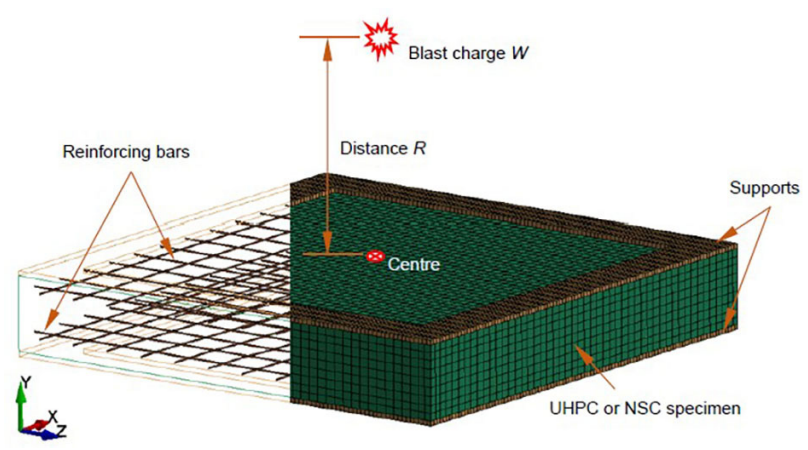

Figure 7. Overview of FE model for the blast simulation of the specimen tested by Yi et al. (2012)

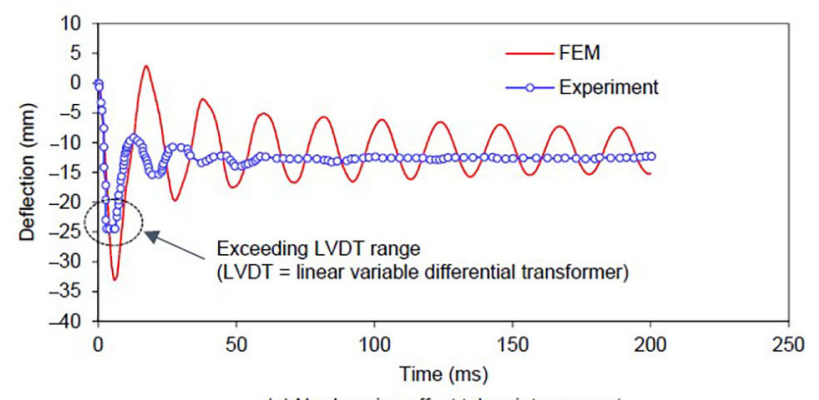

(a) No damping effect taken into account

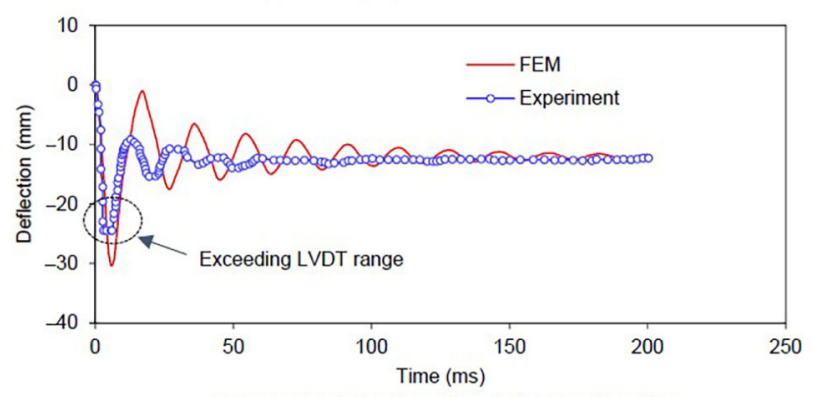

(b) Inclusion of damping ratio of $5 \%$ in the FE model

Figure 8. Deflection time histories for specimen NSC1 tested by Yi et al. (2012) under a blast weight of $15.88 \mathrm{~kg}$ TNT

lation was higher than that measured in the experiment because the maximum deflection that occurred in the experiment exceeded the maximum range of the measurement device for specimen NSC1 under $15.88 \mathrm{~kg}$ TNT, as reported by Yi et al. (2012).

Figure 9(a) and (b) shows the simulated and experimental results for specimen NSC2 subjected to a blast charge of $15.88 \mathrm{~kg}$ ANFO. As shown in Figure 9(b), the numerical results obtained with a damping ratio of $5 \%$ showed good agreement with the experimental results.

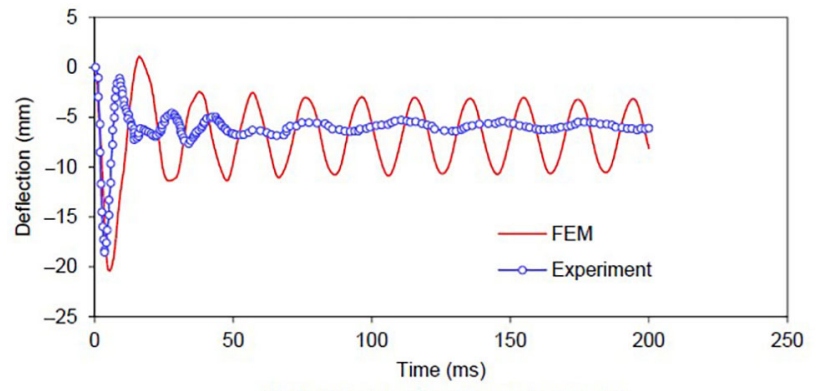

(a) No damping effect taken into account

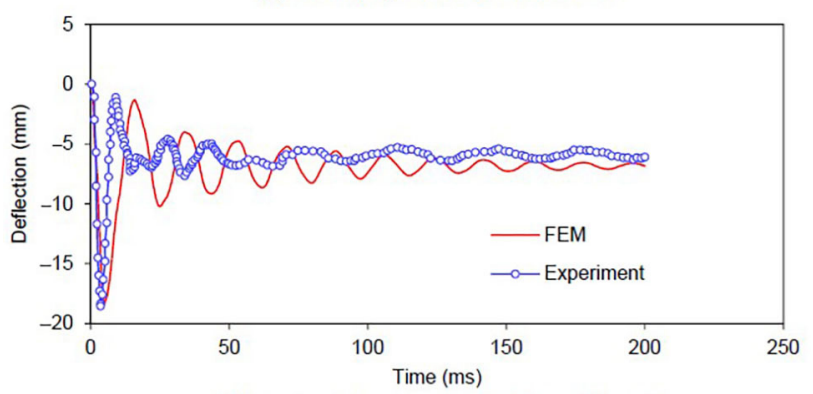

(b) Inclusion of damping ratio of $5 \%$ in the FE model

Figure 9. Deflection time histories for specimen NSC2 tested by Yi et al. (2012) under a blast weight of $15.88 \mathrm{~kg}$ ANFO 


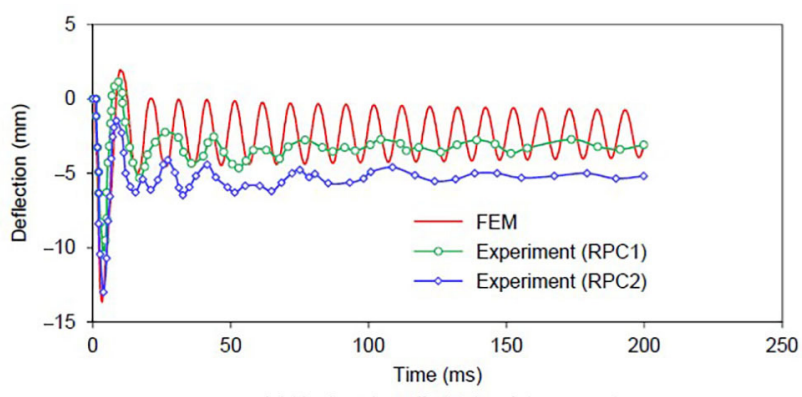

(a) No damping effect taken into account

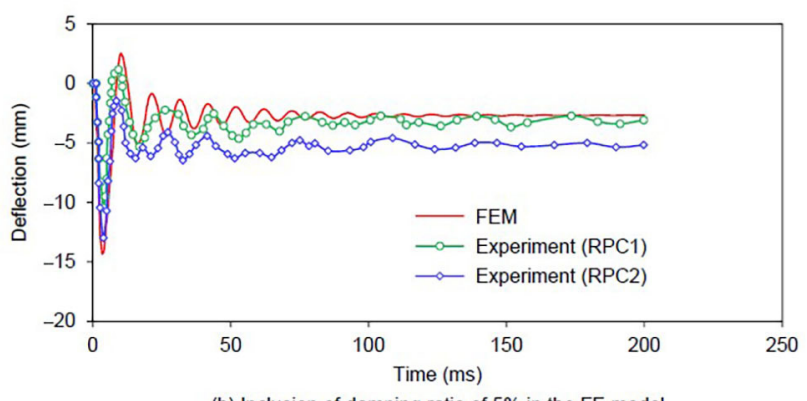

(b) Inclusion of damping ratio of $5 \%$ in the FE model

Figure 10. Deflection time histories for specimens RPC1 and RPC2 tested by Yi et al. (2012) under a blast weight of $15.88 \mathrm{~kg}$ ANFO

Figure 10(a) and (b) respectively show the experimental results and numerical responses without the damping effect and with a damping ratio of 5\% for the UHPC specimens tested by Yi et al. (2012). As shown in Figure 10, when a damping ratio of 5\% was applied in the FE model, the maximum and residual deflections obtained from the numerical simulation agreed well with those of the experimental results.

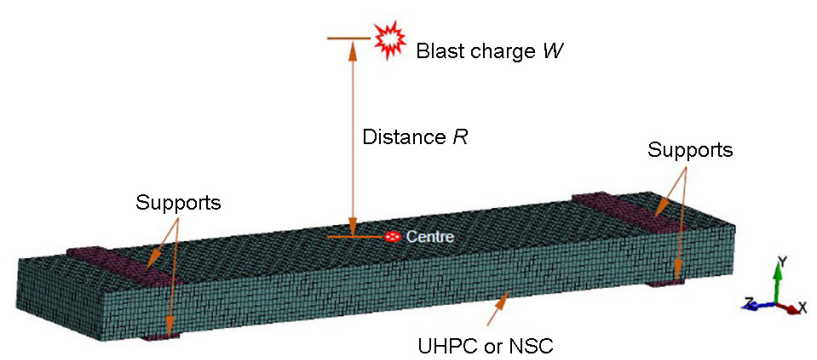

Figure 11. Configuration of FE model for the blast simulation of specimens RE-0 and RE-100

\section{Investigation of static and blast responses of specimens RE-0 and RE-100}

\subsection{Overview of FE model}

Specimens RE-0 and RE-100 tested by Yin et al. (2017) were modelled using a $10-\mathrm{mm}$ mesh. The FE model described in Section 1 and the loading conditions in Section 2 were implemented.

In addition to the static behaviour, the dynamic blast response was numerically investigated in the present study. An overview of the FE model for blast analysis is shown in Figure 11. Supports were modelled using rigid plates and were fixed in all directions. The clear span of the modelled specimens was $1200 \mathrm{~mm}$. The blast performance was assessed by comparing the response of the NSC specimen, RE- 0 , to that of the UHPC specimen, RE-100. A series of 10 different blast charge weights $W$ ranging from 1 to $10 \mathrm{~kg}$ TNT in increments of $1 \mathrm{~kg}$ TNT at a constant distance $R$ of $1.5 \mathrm{~m}$ from the centre of the specimens was applied to each specimen, as shown in Table 3 . In addition, the damping effect was also considered with an assumed damping ratio of $5 \%$, as described in the preceding sections.

Table 3. Blast simulation scenarios and the corresponding results for specimens RE-0 and RE-100

\begin{tabular}{|c|c|c|c|c|c|}
\hline \multicolumn{2}{|c|}{ Parameter } & \multicolumn{3}{c|}{ Simulation results } \\
\hline $\begin{array}{c}\text { Charge distance } R \\
(\mathrm{~m})\end{array}$ & $\begin{array}{c}\text { Charge weight } W \\
(\mathrm{~kg} T \mathrm{TN})\end{array}$ & $\begin{array}{c}\text { Scaled distance } Z \\
\left(\mathrm{~m} / \mathrm{kg}^{1 / 3}\right)\end{array}$ & $\begin{array}{c}\left(\Delta_{\max }\right)_{\mathrm{RE}-0} \\
(\mathrm{~mm})\end{array}$ & $\begin{array}{c}\left(\Delta_{\text {max }}\right)_{\mathrm{RE}-100} \\
(\mathrm{~mm})\end{array}$ & $\frac{\left|\left(\Delta_{\text {max }}\right)_{\mathrm{RE}-100}\right|}{\left|\left(\Delta_{\max }\right)_{\mathrm{RE}-0}\right|}$ \\
\hline 1.5 & 1 & 1.50 & -2.69 & -1.48 & 0.55 \\
\hline 1.5 & 2 & 1.19 & -4.89 & -2.56 & 0.52 \\
\hline 1.5 & 3 & 1.04 & -12.28 & -3.65 & 0.30 \\
\hline 1.5 & 4 & 0.94 & -16.81 & -4.75 & 0.28 \\
\hline 1.5 & 5 & 0.88 & -28.37 & -5.93 & 0.21 \\
\hline 1.5 & 6 & 0.83 & -37.76 & -7.04 & 0.19 \\
\hline 1.5 & 7 & 0.78 & -48.01 & -8.10 & 0.17 \\
\hline 1.5 & 8 & 0.75 & -56.84 & -9.16 & 0.16 \\
\hline 1.5 & 9 & 0.72 & -63.85 & -10.29 & 0.16 \\
\hline 1.5 & 10 & 0.70 & -73.49 & -11.69 & 0.16 \\
\hline
\end{tabular}

Notes: $R$ - distance from the blast charge detonation; $W$ - TNT equivalent charge weight; $Z$ - scaled distance, $Z=R /(W)^{1 / 3}$; $\left(\Delta_{\text {max }}\right)_{\mathrm{RE}-0}-$ maximum deflection for specimen RE-0; $\left(\Delta_{\max }\right)_{\mathrm{RE}-100}-$ maximum deflection for specimen RE-100. 


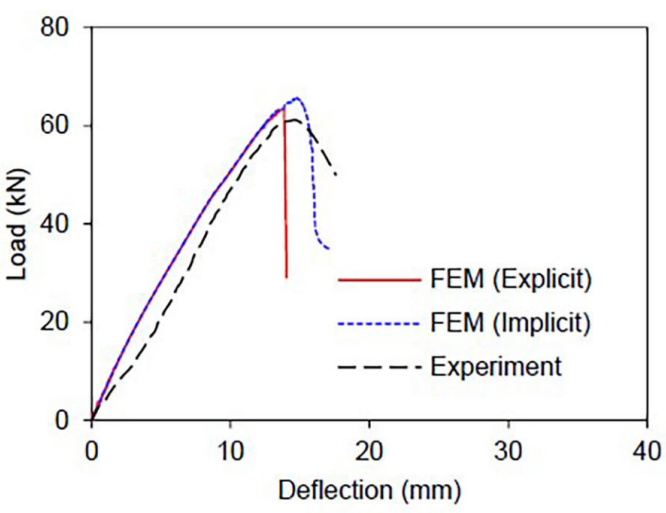

(a) RE-0 (NSC)

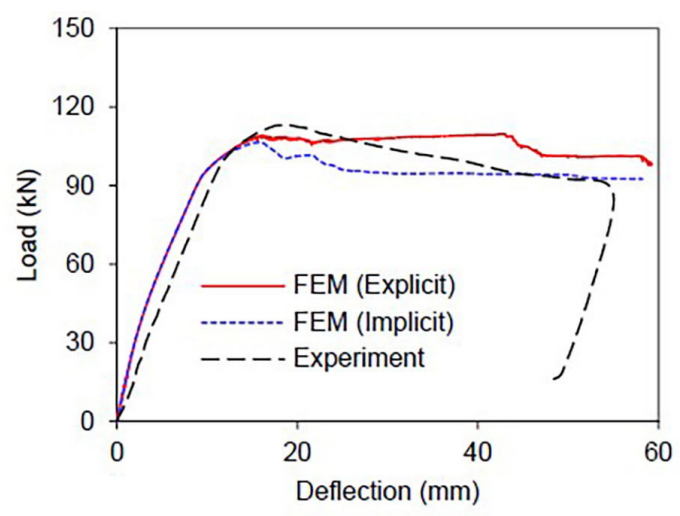

(b) RE-100 (UHPC)

Figure 12. Load-deflection curves under static loading for specimens RE-0 and RE-100

The model parameters used in the numerical simulation of the specimens are given in Table 2. As shown in this table, it should be noted that equal model parameters were applied in both the implicit and explicit methods for RE-0 whereas for RE-100, different sets of concrete model parameters were adopted for the implicit and explicit methods based on the model calibration. The model parameters in Table 2 derived from the static calibration based on the explicit method were used in the blast simulation because the dynamic blast behaviour was assessed in the explicit domain.

\subsection{Simulation results}

\subsubsection{Load-deflection results under static loading}

Figure 12 shows the load-deflection curves obtained from static simulations and the experiments. As shown in Figure 12 , the implicit and explicit load-deflection curves showed similar performance and agreed well with the experimental results for both specimens RE-0 and RE- 100 . It is worth noting that the strength capacity of specimens RE- 0 and RE-100 was analytically predicted by Yin, Shirai, and Teo (2018).

\subsubsection{Comparison of blast responses}

As with the specimens tested by Li et al. (2015) (Section 3.2.1), for the blast simulation, specimens RE-0 and RE-100 were modelled using the model parameters employed in the static FE analysis with the explicit method

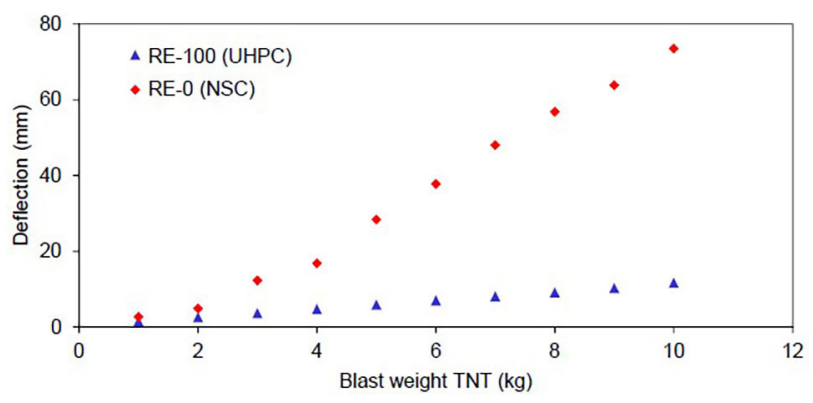

Figure 13. Simulated maximum deflection at the mid-span under different blast weights for specimens RE-0 and RE-100 presented in Section 4.2.1. The simulated blast responses of RE- 0 and RE-100 are compared in this section.

The simulated peak deflection at the mid-span of specimens RE-0 and RE-100 is shown in Figure 13. A summary of simulated maximum deflections of blast responses for RE- 0 and RE-100 is given in Table 3 . The results given in Table 3 demonstrate that the ratio of the maximum deflection of RE-100 to that of RE-0 was remarkably reduced from 0.55 to 0.16 when the blast weight was increased from 1 to $10 \mathrm{~kg}$ TNT. This reduction in the relative deflection is a result of the excellent properties of UHPC.

The simulated deflection time histories under blast weights of 1, 5, and $10 \mathrm{~kg}$ TNT are depicted in Figure 14. As the blast weight increased, the deflection increased for both RE- 0 and RE-100.

Figure 15 shows the simulated blast responses of the NSC specimen RE-0 and UHPC specimen RE-100
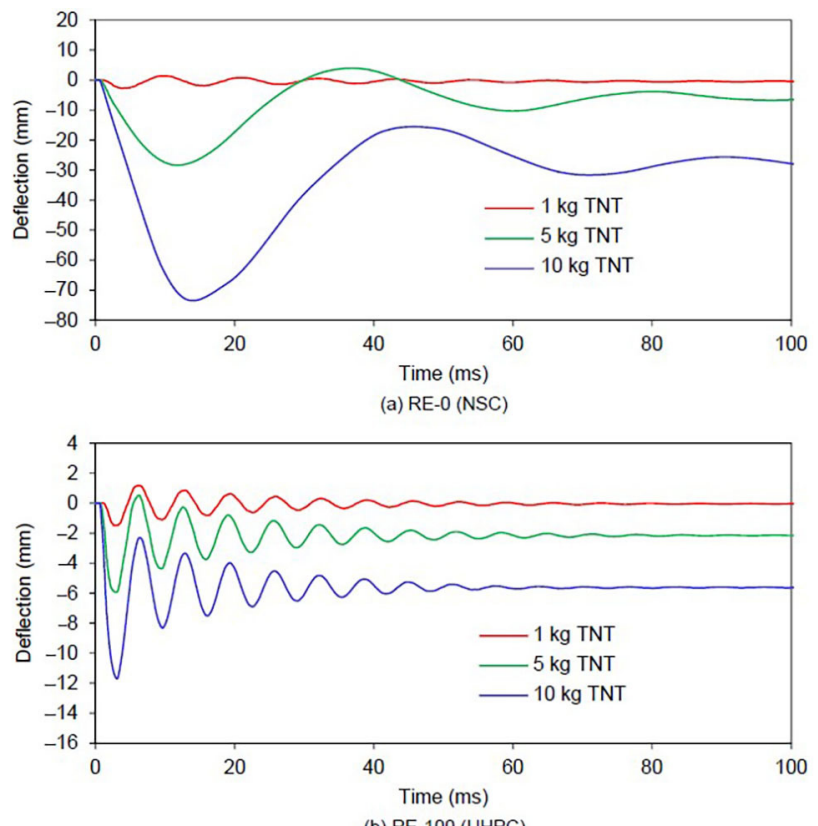

(b) RE-100 (UHPC)

Figure 14. Simulated deflection time histories under blast weights of 1,5 , and $10 \mathrm{~kg}$ TNT for specimens RE- 0 and RE-100 


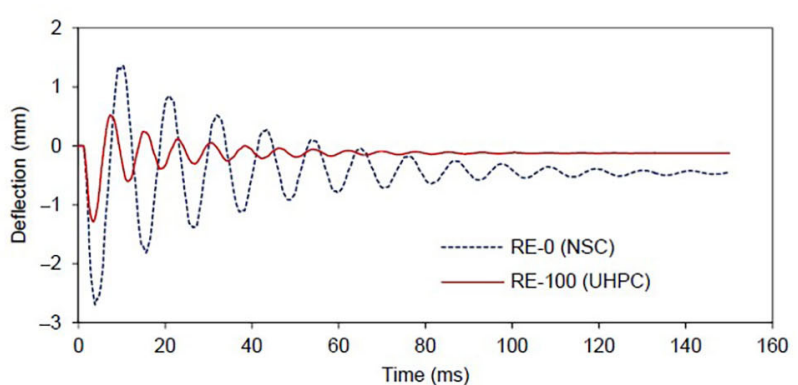

(a) Blast charge weight of $1 \mathrm{~kg}$ TNT
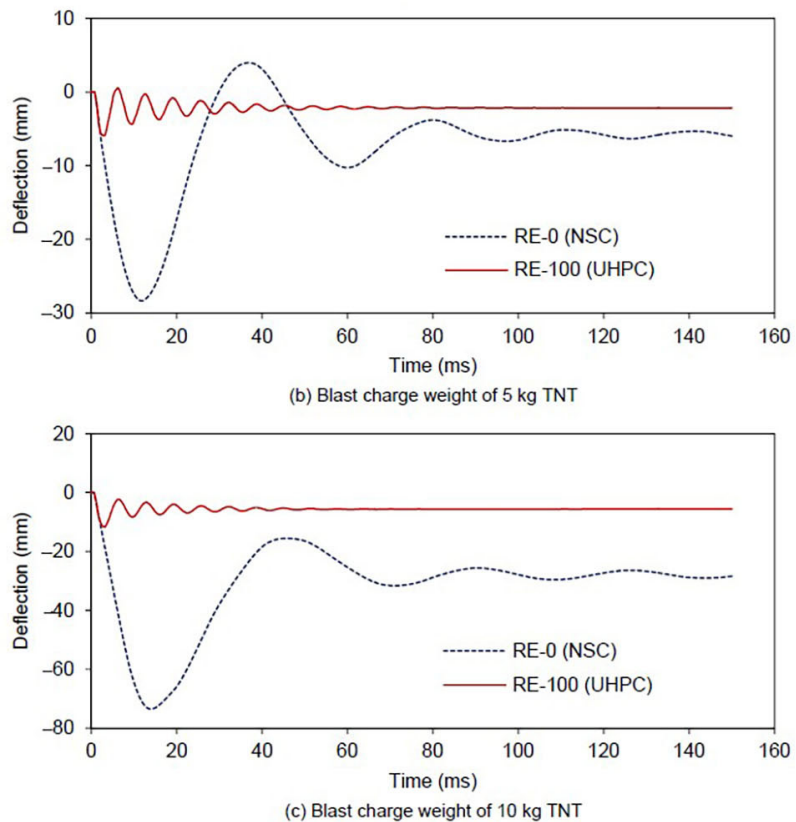

Figure 15. Simulated deflection time histories under different blast weights for RE-0 and RE-100 under three blast loading weights 1,5 , and $10 \mathrm{~kg}$ TNT. It was clearly seen that UHPC significantly enhances blast resistance by reducing the deflection at the midspan of specimen RE-100 compared to those of the specimen $\mathrm{RE}-0$. In addition, as blast charge increased, the difference of response deflection of RE-0 and RE-100 increased.

Figure 16 illustrates the evolution of the shape of the deflection of the clear span of both specimens RE-0 and RE-100 under blast weights of 1 to $10 \mathrm{~kg}$ TNT. As shown in this figure, specimen RE-0 experienced roughly flat deflection in the mid-span zone when it was subjected to blast charges from 5 to $7 \mathrm{~kg}$ TNT as shown in Figure 16(a). This could have been caused by the brittleness and large nonlinearity of NSC, permitting ultimately flat deflection under the large blast charges. Unlike RE-0, specimen RE-100 in the entire range of 1 to $10 \mathrm{~kg}$ TNT showed a smooth deflected shape with a clear peak at the mid-span, as shown in Figure 16(b). This could have been caused by the high strength of the UHPC. These configurations also prove that UHPC effectively enhances the blast effect in comparison with NSC.

Figures 17(a) and 17(b) illustrate the configuration of the effective plastic strain from the numerical simulation of specimens RE- 0 and RE- 100 , respectively. The damage crack pattern of the UHPC specimen, RE-100, was improved relative to that of the NSC specimen, RE- 0 , as a result of the high-performance characteristics of the UHPC, including its high compressibility, tensile strength, and ductility.

\section{Conclusions}

The blast response of UHPC members was assessed using FE analysis in this study. The simulated results were veri-
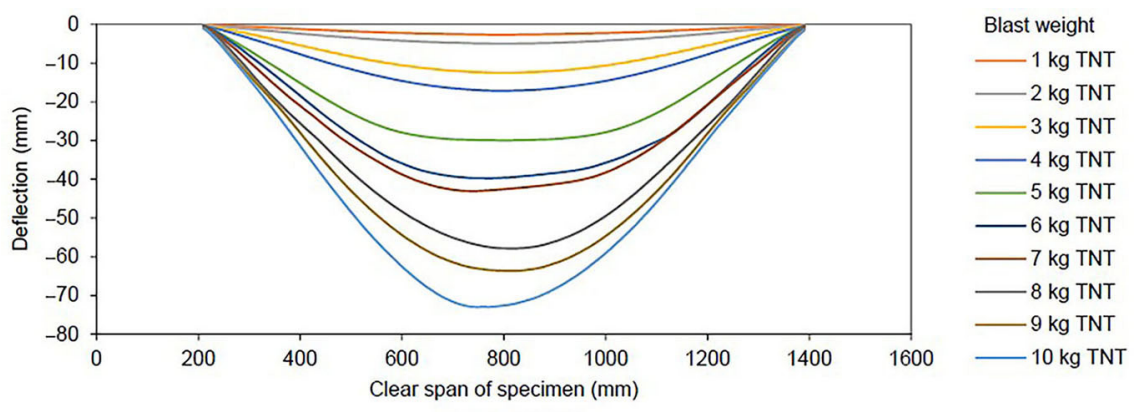

(a) RE-0 (NSC)
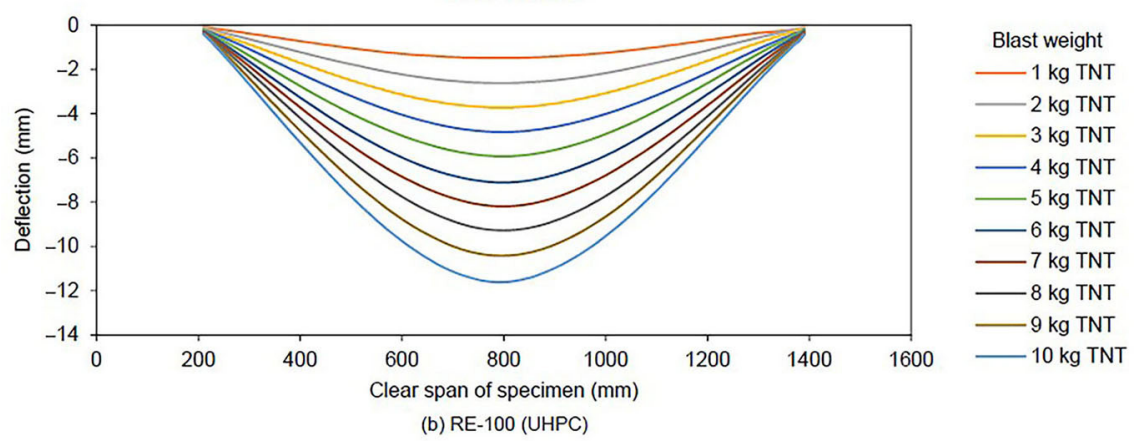

Figure 16. Evolution of deflected shapes under different blast weights for the specimens RE-0 and RE-100 


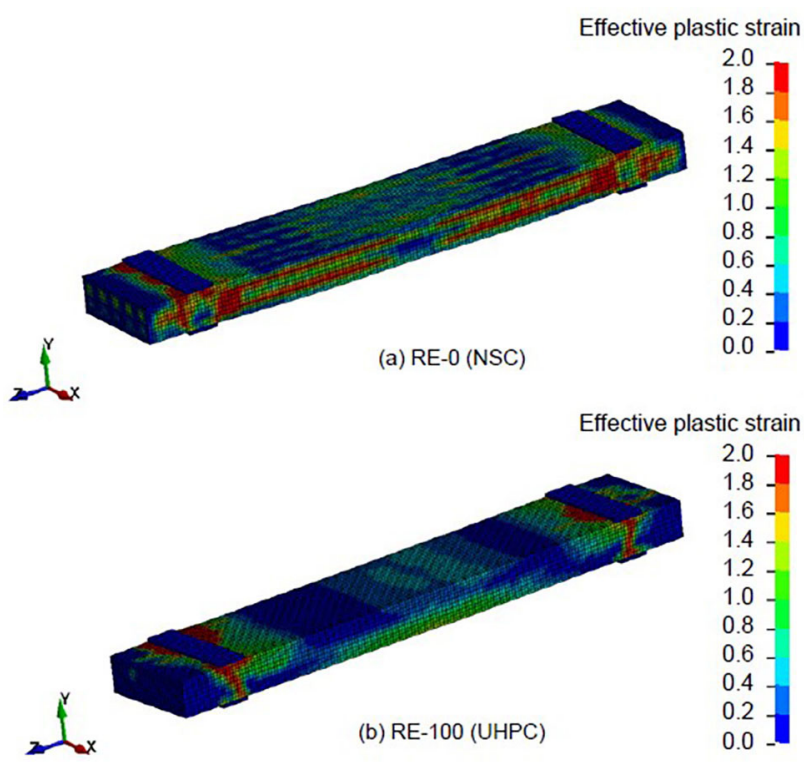

Figure 17. Numerical damage patterns under a blast weight of $5 \mathrm{~kg}$ TNT at $100 \mathrm{~ms}$ for specimens RE-0 and RE-100

fied against experimental results available in the literature. In addition, the responses of UHPC and conventional RC members under varying blast weights were numerically compared. From this study, the following conclusions were drawn:

1. The adopted FE method with an explicit solver derived from static analysis was successfully used in blast simulations and yielded good predictions of the blast response of UHPC members. In comparison with previous experimental results, the numerical simulation provided reasonable agreement.

2. The responses obtained with an assumed damping ratio of $5 \%$ for the members under blast loading to damp the vibration in the FE simulation showed fairly good accuracy.

3. Based on the numerical assessment with various blast weights, the overall response of UHPC members showed significant improvement in comparison with NSC members for every blast weight. The maximum deflection, deflected shape, and damage pattern were enhanced by the high strength and ductile properties of UHPC. This demonstrates that UHPC is suitable for the effective enhancement of the blast performance.

\section{Author contributions}

Hor YIN and Kazutaka SHIRAI were responsible for the FE simulation and wrote the manuscript. Wee TEO and Hor YIN designed the static experiments in Section 4.

\section{Funding}

The authors gratefully acknowledge the financial support from the Toda Scholarship Foundation 2017 Research Grant for this work.

\section{Disclosure statement}

The authors declare that there is no conflict of interests related to this article to disclose.

\section{References}

Brode, H. L. (1955). Numerical solutions of spherical blast waves. Journal of Applied Physics, 26(6), 766-775. https://doi.org/10.1063/1.1722085

CEB-FIP Model Code. (1990). Design code. Comite Euro-International du Beton.

Chen, W., Hao, H., \& Chen, S. (2015). Numerical analysis of prestressed reinforced concrete beam subjected to blast loading. Materials \& Design, 65, 662-674. https://doi.org/10.1016/j.matdes.2014.09.033

Hallquist, J. O. (2016). LS-DYNA keyword users' manual (Vol. 2, version R8.0). Livermore Software Technology Corporation, Livermore, CA.

Li, J., \& Hao, H. (2014). Numerical study of concrete spall damage to blast loads. International Journal of Impact Engineering, 68, 41-55. https://doi.org/10.1016/j.ijimpeng.2014.02.001

Li, J., \& Zhang, Y. (2011). Evolution and calibration of a numerical model for modelling of hybrid-fibre ECC panels under high-velocity impact. Composite Structures, 93(11), 2714-2722. https://doi.org/10.1016/j.compstruct.2011.05.033

Li, J., Wu, C., Hao, H., \& Su, Y. (2015). Investigation of ultra-high performance concrete under static and blast loads. International Journal of Protective Structures, 6(2), 217-235. https://doi.org/10.1260/2041-4196.6.2.217

Li, J., Wu, C., Hao, H., \& Su, Y. (2017). Experimental and numerical study on steel wire mesh reinforced concrete slab under contact explosion. Materials \& Design, 116, 77-91. https://doi.org/10.1016/j.matdes.2016.11.098

Li, J., Wu, C., Hao, H., Wang, Z., \& Su, Y. (2016). Experimental investigation of ultra-high performance concrete slabs under contact explosions. International Journal of Impact Engineering, 93, 62-75. https://doi.org/10.1016/j.ijimpeng.2016.02.007

Lin, X., Zhang, Y., \& Hazell, P. J. (2014). Modelling the response of reinforced concrete panels under blast loading. Materials \& Design, 56, 620-628. https://doi.org/10.1016/j.matdes.2013.11.069

Magallanes, J. M., Wu, Y., Malvar, L. J., \& Crawford, J. E. (2010). Recent improvements to release III of the K\&C concrete model. In $11^{\text {th }}$ International LS-DYNA Users Conference (pp. 3-37-3-48). Livermore Software Technology Corporation, Livermore, CA.

Malvar, L. J., Crawford, J. E., Wesevich, J. W., \& Simons, D. (1997). A plasticity concrete material model for DYNA3D. International Journal of Impact Engineering, 19(9), 847-873. https://doi.org/10.1016/S0734-743X(97)00023-7

Mao, L., Barnett, S. J., Tyas, A., Warren, J., Schleyer, G., \& Zaini, S. (2015). Response of small scale ultra high performance fibre reinforced concrete slabs to blast loading. Construction and Building Materials, 93, 822-830. https://doi.org/10.1016/j.conbuildmat.2015.05.085 
Mao, L., Barnett, S., Begg, D., Schleyer, G., \& Wight, G. (2014). Numerical simulation of ultra high performance fibre reinforced concrete panel subjected to blast loading. International Journal of Impact Engineering, 64, 91-100. https://doi.org/10.1016/j.ijimpeng.2013.10.003

Mays, G., \& Smith, P. D. (1995). Blast effects on buildings: Design of buildings to optimize resistance to blast loading. Thomas Telford.

Millard, S. G., Molyneaux, T. C. K., Barnett, S. J., \& Gao, X. (2010). Dynamic enhancement of blast-resistant ultra high performance fibre-reinforced concrete under flexural and shear loading. International Journal of Impact Engineering, 37(4), 405-413.

https://doi.org/10.1016/j.ijimpeng.2009.09.004

Mills, C. (1987). The design of concrete structure to resist explosions and weapon effects. In Proceedings of the $1^{\text {st }} \mathrm{In}$ ternational Conference on Concrete for Hazard Protection (pp. 61-73).

Ngo, T., Mendis, P., \& Krauthammer, T. (2007). Behavior of ultrahigh-strength prestressed concrete panels subjected to blast loading. Journal of Structural Engineering, 113(11), 1582-1590.

https://doi.org/10.1061/(ASCE)0733-9445(2007)133:11(1582)

Othman, H., Marzouk, H., \& Sherif, M. (2019). Effects of variations in compressive strength and fibre content on dynamic properties of ultra-high performance fibre-reinforced concrete. Construction and Building Materials, 195, 547-556. https://doi.org/10.1016/j.conbuildmat.2018.11.093

Pyo, S., El-Tawil, S., \& Naaman, A. E. (2016). Direct tensile behavior of ultra high performance fiber reinforced concrete (UHP-FRC) at high strain rates. Cement and Concrete Research, 88, 144-156. https://doi.org/10.1016/j.cemconres.2016.07.003

Richard, P., \& Cheyrezy, M. (1995). Composition of reactive powder concretes. Cement and Concrete Research, 25(7), 1501-1511. https://doi.org/10.1016/0008-8846(95)00144-2

Teng, T. L., Chu, Y. A., Chang, F. A., Shen, B. C., \& Cheng, D. S. (2008). Development and validation of numerical model of steel fiber reinforced concrete for high-velocity impact. Computational Materials Science, 42(1), 90-99. https://doi.org/10.1016/j.commatsci.2007.06.013

Thomas, R. J., \& Sorensen, A. D. (2017). Review of strain rate effects for UHPC in tension. Construction and Building Materials, 153, 846-856.

https://doi.org/10.1016/j.conbuildmat.2017.07.168
UFC 3-340-02. (2008). Structures to resist the effects of accidental explosions. US DoD, Washington, DC, USA. Retrieved from https://www.wbdg.org/FFC/DOD/UFC/ARCHIVES/ ufc_3_340_02.pdf

US Department of the Army. (1990). Structures to resist the effects of accidental explosions (Technical manual TM5-1300, NAVFAC P-397, AFR 88-22). Retrieved from https://www.wbdg.org/FFC/ARMYCOE/COETM/ARCHIVES/tm_5_1300_1990.pdf

Wang, Z., Wu, J., \& Wang, J. (2010). Experimental and numerical analysis on effect of fibre aspect ratio on mechanical properties of SRFC. Construction and Building Materials, 24(4), 559-565. https://doi.org/10.1016/j.conbuildmat.2009.09.009

Wille, K., Naaman, A. E., \& Parra-Montesinos, G. J. (2011). Ultra-high performance concrete with compressive strength exceeding $150 \mathrm{MPa}(22 \mathrm{ksi})$ : a simpler way. ACI Materials Journal, 108(1), 46-54. https://doi.org/10.14359/51664215

Wu, C., Oehlers, D., Rebentrost, M., Leach, J., \& Whittaker, A. (2009). Blast testing of ultra-high performance fibre and FRP-retrofitted concrete slabs. Engineering Structures, 31(9), 2060-2069. https://doi.org/10.1016/j.engstruct.2009.03.020

Yi, N. H., Kim, J. H. J., Han, T. S., Cho, Y. G., \& Lee, J. H. (2012). Blast-resistant characteristics of ultra-high strength concrete and reactive powder concrete. Construction and Building Materials, 28(1), 694-707.

https://doi.org/10.1016/j.conbuildmat.2011.09.014

Yin, H., Shirai, K., \& Teo, W. (2018). Prediction of shear capacity of UHPC-concrete composite structural members based on existing codes. Journal of Civil Engineering and Management, 24(8), 607-618.

https://doi.org/10.3846/jcem.2018.6484

Yin, H., Shirai, K., \& Teo, W. (2019a). Finite element modelling to predict the flexural behaviour of ultra-high performance concrete members. Engineering Structures, 183, 741-755. https://doi.org/10.1016/j.engstruct.2019.01.046

Yin, H., Shirai, K., \& Teo, W. (2019b). Numerical model for predicting the structural response of composite UHPC-concrete members considering the bond strength at the interface. Composite Structures, 215, 185-197. https://doi.org/10.1016/j.compstruct.2019.02.040

Yin, H., Teo, W., \& Shirai, K. (2017). Experimental investigation on the behaviour of reinforced concrete slabs strengthened with ultra-high performance concrete. Construction and Building Materials, 155, 463-474.

https://doi.org/10.1016/j.conbuildmat.2017.08.077 